\title{
Estimating Footwear Fit by Using 3D Foot Scans of Shoe Shoppers
}

\author{
Ales JURCA *1,2, Sašo DŽEROSKI ${ }^{3,2}$ \\ ${ }^{1}$ Volumental AB, Stockholm, Sweden; \\ 2 Jožef Stefan Postgraduate School, Ljubljana, Slovenia \\ ${ }^{3}$ Jožef Stefan Institute, Ljubljana, Slovenia \\ https://doi.org/10.15221/21.51
}

\begin{abstract}
Shoes are available in multiple sizes and widths to accommodate the anatomic variation of human feet. Several footwear sizing systems are being used to indicate the size and width of footwear: UK, US, EU, and mondopoint. Shoe sizes are supposed to help retail customers buy well-fitting shoes. Ideally, all shoes labeled with the same size and width should provide the same fit. However, physical measurements and $x$-ray images of shoes of the same size have shown inconsistent internal lengths and widths. The aim of this study was to estimate the fit of women's running shoes, utilizing foot scans and purchase data of shoe shoppers.
\end{abstract}

A dataset of over 90,000 3D foot scans and matched running shoes labeled US size 9 medium width was used in this study. Each shoe shopper purchased one of 841 running models of 14 most popular running brands. The optimal foot length and width for each model was calculated using hundreds or even thousands of foot scans of customers that bought that model in US size 9 medium width.

Results show a large dispersion of optimal foot lengths and widths for running models that are all labeled with the same size and width. Only $60 \%$ of the models in this study fitted as a true US 9 medium. A large dispersion of optimal foot length was observed for shoe styles within most footwear brands.

Keywords: footwear fit, footwear true size, 3D foot scans

\section{Introduction}

Previous studies have shown a large dispersion of foot measurements within the same length class [1]. Shoes are available in multiple sizes and widths to accommodate the anatomic variation of human feet. There are four main sizing systems at play in the industry to indicate the size and width of footwear (UK, US, EU and Mondopoint). They use different length intervals between sizes and different starting points. A length increment of $4.23 \mathrm{~mm}$ for half sizes and width increment of $4.76 \mathrm{~mm}$ for widths is used for the US sizing system [2]. The UK sizing system has the same length increment as the US sizing system, but uses a different starting point. A length increment for the EU sizing system is $6.66 \mathrm{~mm}$. It's not clear if existing shoe size standards refer to foot or shoe length, and the optimal difference between the foot and shoe length is not defined. Almost every footwear brand has its own interpretation of the sizing standards.

Shoe sizes are supposed to help shoe shoppers buy the right size. Ideally, all shoes labeled with the same size and width should provide the same fit. Yet, physical measurements [3,4] and x-ray images [5] of shoes with the same size showed inconsistent internal lengths and widths.

Measuring the fit of a shoe is a challenging task. In the past, several methods have been used to capture the actual shoe size and fit. Mechanical devices are used to measure the inside length of shoes. However, the fit of a shoe depends on many other parameters like ball width and girth, instep girth and height, and many more, therefore, the inside length measurement doesn't really provide information about the actual shoe fit. Optical 3D scans of the shoe's inside surface capture the inside surface of an empty shoe, but the internal shoe shape changes significantly with a foot in the shoe. Therefore, measuring an empty shoe is not really useful.

X-ray and CT scans of shoes have a similar problem as the optical 3D scans because it is really difficult to simulate a foot inside the shoe while performing a scan

Meanwhile, advancements in using foot scanning technology in retail enables collecting foot scans and purchasing information of shoe shoppers. In a previous study [6], we proposed a novel method of evaluating the fit of footwear by leveraging large datasets of foot scans and purchase data. The aim of this study was to evaluate the consistency of women's running shoes by applying the same method.

*ales.jurca@volumental.com; www.volumental.com 


\section{Methods}

\subsection{Data collection}

This study was conducted using a 3D foot scan database of millions of female shoe shoppers, who got their feet scanned in one of the footwear brick and mortar stores according to the method described in [1]. 90,720 foot scans of shoppers who bought at least one of the 841 women's running shoes in size US 9 medium width, and were not returned after the purchase, were used in this study. For each shopper, foot length and width of the longer foot was extracted from the 3D scans.

\subsection{Calculation of the optimal foot length and width}

Extracted foot lengths and widths of all shoe shoppers who purchased a shoe style in size US 9 medium were used to evaluate the fit of that shoe style. A bivariate kernel density estimate (KDE) method was used to estimate a probability density function of foot length and width for each shoe style. An optimal foot length and width of a shoe style was calculated as the peak of the probability density function of the style. Probability density functions for two styles are presented in Fig.1. Optimal foot lengths and widths are indicated with vertical and horizontal blue lines. Optimal foot length and width for the style A on the left are $251.7 \mathrm{~mm}$ and $94.9 \mathrm{~mm}$, and for the style B on the left are $245.0 \mathrm{~mm}$ and $89.7 \mathrm{~mm}$. These results indicate that style $A$ fits to larger and wider feet versus style B, even though both styles are labeled with size US 9 medium.

Optimal foot lengths and widths of all 841 styles were compared in a scatter plot to compare the consistency of fit across all the styles. A mean foot length and width across all the styles was calculated to indicate the average fit of all styles in size US 9 medium.
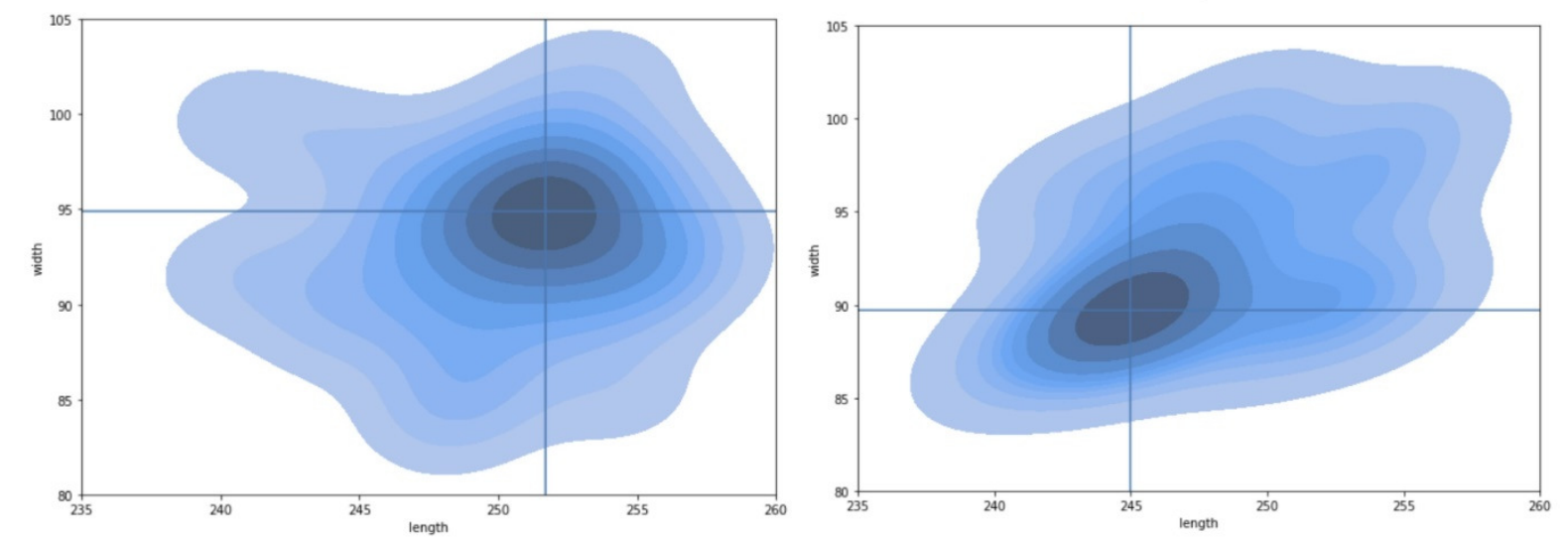

Fig. 1. Probability density functions of foot lengths and widths for two shoe styles.

\section{Results}

A scatter plot of optimal foot lengths and widths for all 841 shoe styles in size US 9 medium is presented in Fig 2. Each dot in this chart represents one of the 841 styles. The horizontal position of each dot indicates the optimal foot length for that style, and the vertical position of each dot indicates the optimal foot width for that style in size US 9 medium. The vertical and horizontal lines represent the mean optimal foot length $(249.1 \mathrm{~mm})$ and width $(94.0 \mathrm{~mm})$. 


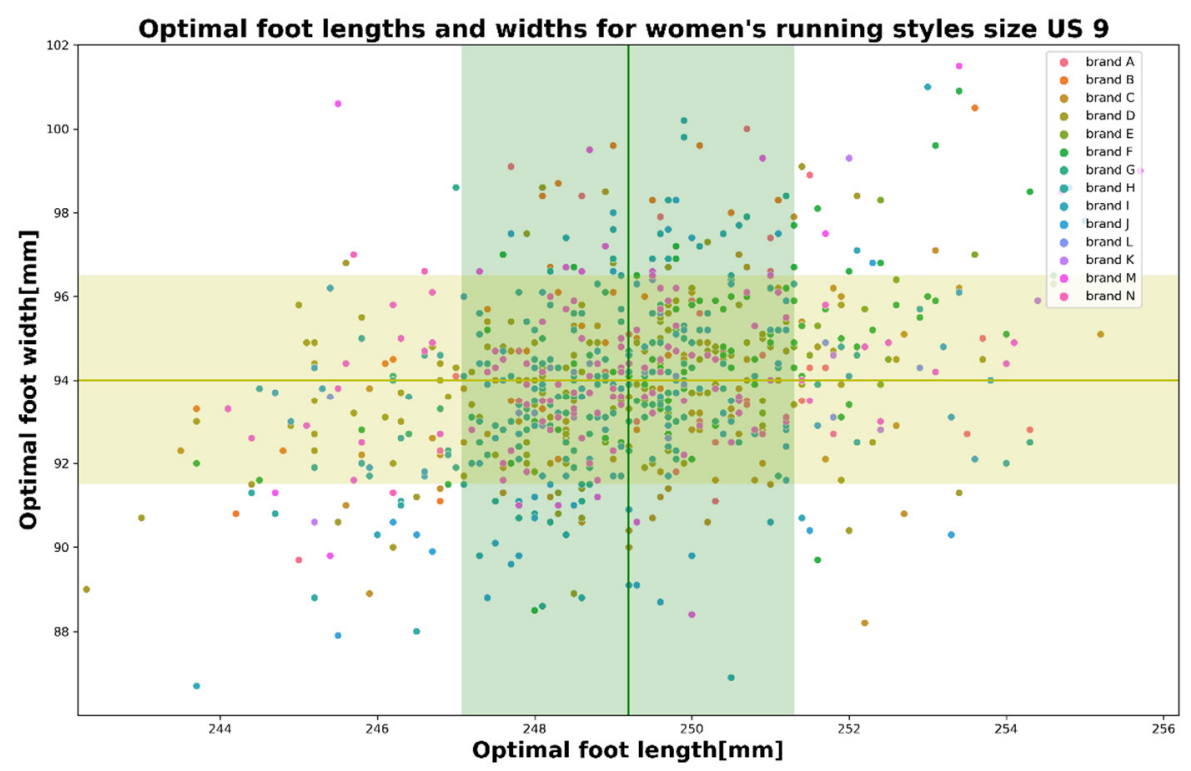

Fig. 2. Optimal foot lengths and widths for 841 women's running shoe styles in size US 9 medium.

The vertical green area and the horizontal yellow area show the range of one US size and width around the mean values. Shoe styles located in the overlapping area of both bars $(60 \%$ of all the styles in US 9) fit as a true size US 9 medium width, styles outside this area fit larger, smaller, narrower or wider.

Below, Fig. 3 shows a distribution of optimal foot lengths for styles within each anonymized brand. Each dot represents one of the 841 styles. Dots of the same color represent styles of one (anonymized) brand. The vertical location of a dot indicates the optimal foot length of the style. The horizontal line indicates the mean optimal foot length across all 841 styles.

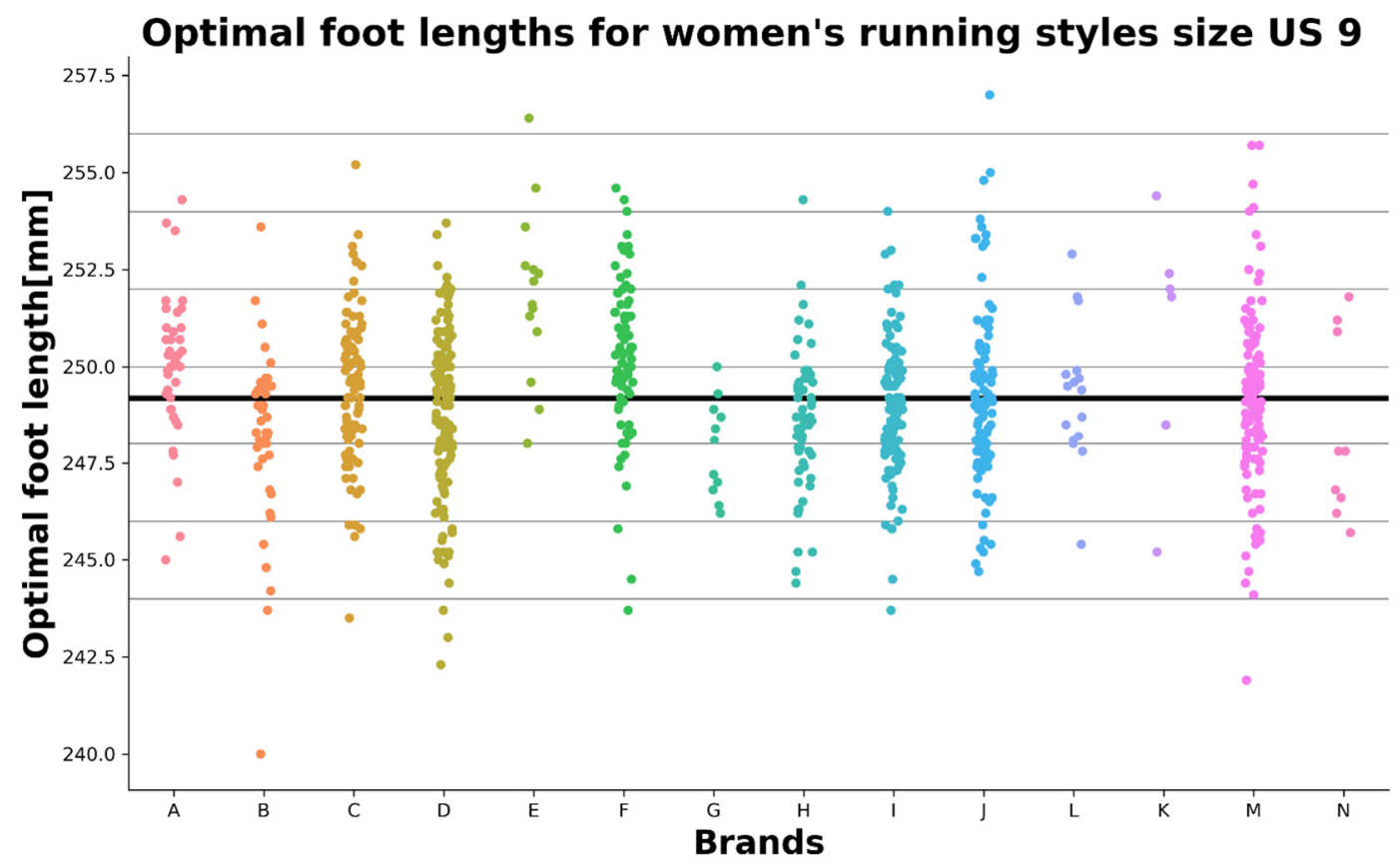

Fig. 3. Distribution of optimal foot length across shoe styles grouped by brand. 


\section{Discussion and conclusions}

A novel method of evaluating the fit of footwear by leveraging large datasets of foot scans and purchase data was previously used to evaluate the fit of men's running shoes. In the present study, the same method was used to evaluate the fit of women's running shoes. The results of this study demonstrate the foot lengths and widths of shoppers who purchased shoes labeled with US 9 medium width; $40 \%$ of the shoe styles did not fit as US 9 medium, even though the shoes are labeled as such. The percentage of such women's styles is even higher compared to men's shoes (37\%).

As depicted in Fig. 3, shoes across most brands vary a great deal in terms of the optimal foot length. As you can see most of brand $E$ styles run larger than the average US 9, and most of brand G styles run smaller than the average US 9.

Inconsistent size labels can be confusing for shoe shoppers when searching for perfectly fitting shoes, especially for online shoppers. Footwear brands could improve the consistency of shoe sizes, but because of all the factors that influence the fit of shoes like material and production method, there will always be some size variation. For that reason, the solution to inconsistent sizing is to apply technology methods such as Al and machine learning to solve the current fit dilemma.

\section{References}

[1] Jurca, A., Žabkar, J. \& Džeroski, S. Analysis of 1.2 million foot scans from North America, Europe and Asia. Sci Rep 9, 19155 (2019). https://doi.org/10.1038/s41598-019-55432-z.

[2] Luximon, Y. \& Luximon, A. (2013). Sizing and grading of shoe lasts. In Luximon, A. (ed.) Handbook of Footwear Design and Manufacture, Woodhead Publishing Series in Textiles, 197-215.

[3] Jastifer, J., Kent, R., Crandall, J., Sherwood, C., Lessley, D., McCullough, K. A., Coughlin, M. J., \& Anderson, R. B. (2017). The Athletic Shoe in Football: Apparel or Protective Equipment? Sports Health,9(2),126-131. https://doi.org/10.1177/1941738117690717.

[4] Wannop JW, Stefanyshyn DJ, Anderson RB, Coughlin MJ, Kent R. (2019). Development of a Footwear Sizing System in the National Football League. Sports Health, 11(1),40-46. https://doi.org/10.1177/1941738118789402.

[5] Jurca, A. \& Dzeroski, S. (2013). Length dispersion of shoes labelled with the same size in the UK shoe-size system, Footwear Science, 5(sup1), S39-S41. https://doi.org/10.1080/19424280.2013.799543.

[6] Jurca, A. \& Dzeroski, S. (2021). Fit consistency of men's running shoes, Footwear Science, 13:sup1, S63-S65. https://doi.org/10.1080/19424280.2021.1917683. 